Published in final edited form as:

ACS Appl Mater Interfaces. 2016 June 08; 8(22): 13804-13811. doi:10.1021/acsami.6b03737.

\title{
Light-Responsive Biodegradable Nanomedicine Overcomes Multidrug Resistance via NO-Enhanced Chemosensitization
}

\author{
Jing Fan ${ }^{\dagger, \ddagger, \S}$, Qianjun $\mathrm{He}^{\perp}$, Yi Liü ${ }^{\ddagger}$, Fuwu Zhang ${ }^{\ddagger}$, Xiangyu Yang $^{\dagger, \ddagger}$, Zhe Wang ${ }^{\ddagger}$, Nan Lu ${ }^{\ddagger}$, \\ Wenpei Fan ${ }^{\ddagger}, \perp$, Lisen Lin ${ }^{\ddagger}$, Gang Niu ${ }^{\ddagger}$, Nongyue $\mathrm{He}^{\dagger}$, Jibin Song ${ }^{\ddagger}$, and Xiaoyuan Chen ${ }^{\ddagger}$ \\ tState Key Laboratory of Bioelectronics, Southeast University, Nanjing 210096, Jiangsu, P.R. \\ China \\ ‡Laboratory of Molecular Imaging and Nanomedicine (LOMIN), National Institute of Biomedical \\ Imaging and Bioengineering (NIBIB), National Institutes of Health, Bethesda, Maryland 20892, \\ United States \\ ${ }^{\perp}$ Guangdong Key Laboratory for Biomedical Measurements and Ultrasound Imaging, Department \\ of Biomedical Engineering, School of Medicine, Shenzhen University, Shenzhen 518060, \\ Guangdong, P.R. China \\ §Biological Target Diagnosis \& Treatment Center, Guangxi Medical University, Nanning 530021, \\ Guangxi, P.R. China
}

\begin{abstract}
Multidrug resistance (MDR) is responsible for the relatively low effectiveness of chemotherapeutics. Herein, a nitric oxide (NO) gas-enhanced chemosensitization strategy is proposed to overcome MDR by construction of a biodegradable nanomedicine formula based on BNN6/DOX coloaded monomethoxy(polyethylene glycol)-poly(lactic-co-glycolic acid) (mPEGPLGA). On one hand, the nanomedicine features high biocompatibility due to the high density of PEG and biodegradable PLGA. On the other hand, the nanoformula exhibits excellent stability under physiological conditions but exhibits stimuli-responsive decomposition of BNN6 for NO gas release upon ultraviolet-visible irradiation. More importantly, after NO release is triggered, gas molecules are generated that break the nanoparticle shell and lead to the release of doxorubicin. Furthermore, NO was demonstrated to reverse the MDR of tumor cells and enhance the chemosensitization for doxorubicin therapy.
\end{abstract}

\section{Graphical Abstract}

Correspondence to: Nongyue He; Jibin Song; Xiaoyuan Chen.

\section{ASSOCIATED CONTENT}

Supporting Information

The Supporting Information is available free of charge on the ACS Publications website at DOI: 10.1021/acsami.6b03737.

DOX standard curve, mPEG-PLGA-BNN6-DOX loading amount and efficiency, Griess assay that detected the NO release of mPEGPLGA-BNN6, UV-vis monitored DOX release, ${ }^{1}$ H NMR spectrum of the mPEG-PLGA copolymer, and the DOX standard curve by HPLC (PDF)

The authors declare no competing financial interest. 


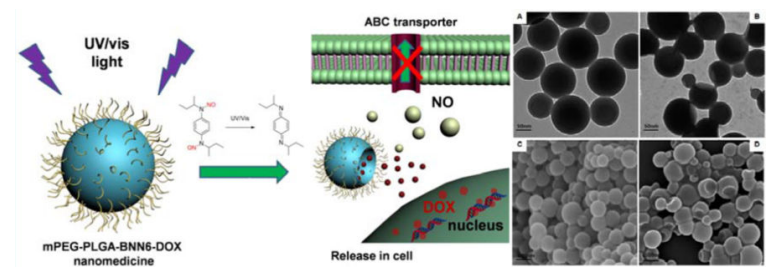

\section{Keywords}

nitric oxide (NO); light-responsive; mPEG-PLGA; chemotherapy; multidrug resistance (MDR)

\section{INTRODUCTION}

Multidrug resistance (MDR) is a primary challenge in tumor therapy because it can cause the failure of chemotherapy or the need to increase the effective dosage of chemotherapy drugs. A change in $\mathrm{pH}$ or signal molecules can change the membrane permeability of tumor cells to some molecules, especially chemotherapy drugs, which leads to decreased chemosensitization, reflected by the inability of extracellular molecules to enter cells and the rapid pumping out of intracellular molecules. ${ }^{1}$ The classic MDR pathway is usually mediated by ATP-binding cassette $(\mathrm{ABC})$ transporters, including P-glycoprotein (P-gp), multidrug resistance-associated protein (MRP), lung resistance protein (LRP), ${ }^{2}$ and breast cancer resistant protein (BCRP). ${ }^{3}$ Most of these serve as transmembrane efflux pumps that eliminate exogenous substrates out of cells or the nucleus under the action of ATP. ${ }^{4-6}$ Normal expression of $\mathrm{ABC}$ transporters in normal tissues and cells maintains the regulation of physical and defensive functions. However, overexpression of $\mathrm{ABC}$ transporters in MDR tumor cells seriously increases the efflux of anticancer drugs such as anthracyclines, taxanes, vinca alkaloids, and epipodophyllotoxins. ${ }^{7}$ The hypoxic environment and oxidative stress of tumor tissues are known to affect and increase the expression of ABC transporters, ${ }^{8-10}$ which probably leads to adaptations such as enhancement of invasive and metastatic capabilities ${ }^{11}$ or vascular proliferation in tumor tissues. ${ }^{12,13}$ Several types of cancer which feature increased hypoxia and excessive reactive oxygen species (ROS) were observed in patients with a shorter lifespan. ${ }^{14-16}$ Therefore, reducing agent treatment is expected to play a vital role in anti-MDR through the release of oxidative stress of tumors.

Recently, both experimental and clinical studies indicate that nitric oxide (NO) as a chemosensitizer can effectively reverse MDR and restore the cytotoxicity of chemotherapeutics against tumor cells. ${ }^{17-21} \mathrm{NO}$ is an odorless, colorless, lipophilic, highly diffusible, and short-lived radical molecule. It reacts with ROS in tumor tissue and relieves oxidative stress to inhibit the activation of the tolerance and scavenging systems of tumor cells. ${ }^{22,23} \mathrm{NO}$ is also able to conjugate with heme groups of molecules such as soluble guanylyl cyclase (sGC), which is a classic downstream signal molecule of the NO pathway. ${ }^{24,25}$ After binding with NO, the heme maintains the "oxy" conformation in hypoxic environments, and the downstream pathway would not be activated, which deactivates the transport proteins. ${ }^{26}$ 
In this research, a biodegradable nanomedicine based on a BNN6/DOX coloaded monomethoxy(polyethylene glycol)- poly(lactic-co-glycolic acid) (mPEG-PLGA) nanoparticle has been constructed for UV-vis-responsive NO and DOX release. Here, PLGA with a 50/50 ratio of lactide (LA) to glycolide (GA) was chosen because it has a rapid degradation rate under physiological conditions. ${ }^{27}$ The size (in nanometers) and high surface density of mPEG provide the nanoparticles with a relatively long blood circulation time and enhanced tumor accumulation, which is favored for cancer therapy. The NO donor BNN6 is sensitive to UV-vis illumination for NO release. ${ }^{28}$ The generated NO gas is able to break the nanoparticle shell and promote the release of wrapped DOX molecules, leading to a remarkable gas/drug effect that reverses MDR via NO-sensitized DOX efficacy enhancement (Figure 1).

\section{MATERIALS AND METHODS}

\subsection{Synthesis and Characterization of BNN6}

$N, N^{\prime}$-di-sec-Butyl- $N, N^{\prime}$-dinitroso-1,4-phenylenediamine (BNN6) was synthesized as reported previously; ${ }^{28} 2.34 \mathrm{~mL}$ (10 mmol) of $N, N^{\prime}$-bis-sec-butylamino- $p$-phenylenediame (BPA, TCI America) was added to $18 \mathrm{~mL}$ of ethanol, and then $20 \mathrm{~mL}$ of a $6 \mathrm{M}$ degassed aqueous solution of $\mathrm{NaNO}_{2}$ (Sigma-Aldrich) was added under stirring and nitrogen protection. After $30 \mathrm{~min}, 20 \mathrm{~mL}$ of a $6 \mathrm{M}$ aqueous solution of $\mathrm{HCl}$ was added dropwise through a separating funnel. The reaction solution color gradually changed from orange to red, and the reaction yielded a beige precipitate. After being stirred for $4 \mathrm{~h}$, the solid product was collected by centrifugation at $1000 \mathrm{rpm}$ for $15 \mathrm{~min}$. The collected precipitate was washed with water and $50 \%(\mathrm{v} / \mathrm{v})$ ethanol/water in turn three times to remove residual reactants and then dried under freezing vacuum in a dark environment overnight. The structure of the synthesized BNN6 was tested by ${ }^{1} \mathrm{H}$ NMR (Bruker Magnet System, 300 $\mathrm{MHz} / 54 \mathrm{~mm}$ ) and mass spectrometry (Waters LC-MS System) measurements. ${ }^{1} \mathrm{H}$ NMR (300 MHz, $\left.\mathrm{CDCl}_{3}\right): \delta 7.52(4 \mathrm{H}), 4.95-4.69(2 \mathrm{H}), 2.00-1.84(2 \mathrm{H}), 1.81-1.69(2 \mathrm{H}), 1.48(\mathrm{t}, J$ $=7.6 \mathrm{~Hz}, 6 \mathrm{H}), 1.08(\mathrm{td}, J=7.4,5.3 \mathrm{~Hz}, 6 \mathrm{H})$. MS $\left(\mathrm{ESI}^{+}\right)$: calcd for $\mathrm{C}_{14} \mathrm{H}_{22} \mathrm{~N}_{4} \mathrm{O}_{2}[\mathrm{M}]^{+} 278.2$. Found $[\mathrm{M}]^{+} 279.2$.

\subsection{Synthesis of mPEG-PLGA Block Copolymer}

For the synthesis of mPEG-PLGA, $1.5 \mathrm{~g}$ of LA (Sigma-Aldrich), $1.2 \mathrm{~g}$ of GA (SigmaAldrich), and $2.5 \mathrm{~g}$ mPEG-OH (MW $=5000$, Sigma-Aldrich) were added to a flask with nitrogen for $30 \mathrm{~min}$. Then, $10 \mu \mathrm{L}$ of tin(II) 2-ethylhexanoate (Sigma-Aldrich) was added, and the solution was flushed with nitrogen for $10 \mathrm{~min}$. The polymerization of LA and GA was carried out at $130^{\circ} \mathrm{C}$ for $30 \mathrm{~h}$. The resulting mixture was cooled to room temperature, dissolved in $10 \mathrm{~mL}$ of tetrahydrofuran (THF, Sigma-Aldrich), precipitated into cold hexane three times, and dried under vacuum to obtain the product as a white solid. ${ }^{1} \mathrm{H}$ NMR data: $3.72\left(-\mathrm{O}-\mathrm{CH}_{2} \mathrm{CH}_{2}-\right), 1.61\left(-\mathrm{CH}_{3}\right), 4.82$ (-CO-CH-O), 5.28 (-CO- $\left.\mathrm{CH}_{2}-\mathrm{O}-\right)$ (Figure S5).

\subsection{Preparation and Characterization of mPEG-PLGA-BNN6 and mPEG-PLGA-BNN6-DOX Nanoparticles}

We utilized a microemulsion strategy to prepare the mPEG-PLGA-BNN6-DOX nanomedicine. A mixture of $2 \mathrm{mg}$ of lyophilized mPEG-PLGA copolymer, $1 \mathrm{mg}$ of BNN6, 
and $1 \mathrm{mg}$ of doxorubicin was dissolved in $100 \mu \mathrm{L}$ of dichloromethane under sonication for 20 s. One milliliter of a $0.2 \%$ SDS (sodium lauryl sulfate, Sigma-Aldrich)/water solution was added to the solution, and then the mixture was sonicated for $1 \mathrm{~min}$ to form an oil-inwater emulsion. The emulsion solution was then stirred at room temperature for $12 \mathrm{~h}$ to evaporate the dichloromethane. After the solution became clear, the mPEG-PLGA-BNN6DOX nanomedicine was purified by centrifugation at $8000 g$ for $5 \mathrm{~min}$. Because BNN6 is sensitive to UV-vis light, all of these operations were done in a dark environment. The mPEG-PLGA-BNN6 nanoparticles were prepared using the same procedure but without DOX. The as-prepared mPEG-PLGA-BNN6 nanoparticles were treated with $365 \mathrm{~nm}$ light irradiation to trigger the release of NO from BNN6. Then, the morphology of the mPEGPLGA-BNN6-DOX nanomedicine was characterized by transmission electron microscopy (TEM, JEM 2010 electron microscope, Jeol Ltd.) and scanning electron microscopy (SEM, SU-70 Schottky field emission gun scanning electron microscope, Hitachi Inc.). The mPEGPLGA-BNN6-DOX nanoparticles without UV light treatment were set as a control. The zeta potential and size of the mPEG-PLGA-BNN6-DOX nanoparticles were measured by a nanoparticle analyzer (SZ-100, HORIBA). UV- vis spectrophotometry (Genesys 10S UVvis spectrophotometer, Thermo Scientific) was applied to detect the loading of BNN6 and doxorubicin in the mPEG-PLGA copolymer. A standard curve of concentrations of DOX in PBS solution from 1.56 to $100 \mu \mathrm{g} / \mathrm{mL}$ was established to calculate the DOX loading amount and efficiency in the mPEG-PLGA micelles.

\subsection{Nitric Oxide Release Property of mPEG-PLGA-BNN6 Nanoparticles}

The classic Griess method (Promega) for detecting NO release in a PBS (pH 7.4) solution was utilized in this experiment to measure the stability and release properties of the mPEGPLGA-BNN6 nanoparticles, in which the NO donor BNN6 particles were wrapped inside. Two hundred microliters of the sample was mixed with $200 \mu \mathrm{L}$ of a sulfanilamide solution ( $1 \%$ sulfanilamide in $5 \%$ phosphoric acid), and then the mixture was shaken for 10 min at room temperature in the dark. A NED solution $(0.1 \% \mathrm{~N}$-1-naphthylethyle-nediamine dihydrochloride in water, $200 \mu \mathrm{L}$ ) was added to the mixture, and the solution mixture was incubated for $10 \mathrm{~min}$ at room temperature in the dark. Finally, the mixture was measured using a UV-vis spectrophotometer. $\mathrm{NaNO}_{2}$ standard samples $(0.05-25 \mu \mathrm{M})$ were used to establish a standard curve for the calculation of $\mathrm{NO}$ concentrations. Three groups were set in this research: the mPEG-PLGA-BNN6 UV group was treated with $365 \mathrm{~nm}$ light irradiation for $2 \mathrm{~min}$ and then tested using a Griess assay, the mPEG-PLGA-BNN6 control group with the same amount of mPEG-PLGA-BNN6 was placed in a $37{ }^{\circ} \mathrm{C}$ dark environment for 5 days and tested every day, and the mPEG-PLGA-BNN6 LED lamp group was treated with LED lamp (Personal Lighting System, Finelite Inc.) irradiation for $1 \mathrm{~h}$ and then tested using a Griess assay.

\subsection{DOX Release Behavior of mPEG-PLGA-BNN6-DOX after UV Light Treatment in PBS Solution}

The obtained mPEG-PLGA-BNN6 nanomedicine was exposed to $365 \mathrm{~nm}$ light for $2 \mathrm{~min}$ to trigger $\mathrm{NO}$ gas generation and break the shells of the micelles to release the wrapped doxorubicin; then, the nanoparticles were kept in a $37^{\circ} \mathrm{C}$ dark environment, and DOX 
release was monitored by UV-vis spectrophotometry (Figure S1). A control group without UV light irradiation was applied to test the effect of NO release.

\subsection{Intercellular NO Release Detection with an RBSP Fluorescence Probe}

A NO detection fluorescence probe based on rholdamine $\mathrm{B}(\mathrm{RhB})$ was prepared and utilized in this research. The probe synthesis followed a previously reported method; ${ }^{28,29}$ briefly, 0.4 mmol RhB was dissolved in $20 \mathrm{~mL}$ of a chloroform solution. Then, $8 \mathrm{mmol} \mathrm{o}-$ phenylenediamine and $0.4 \mathrm{mmol}$ (benzotriazol-1-yloxy)-tripyrrolidinophosphonium hexafluorophosphate were added and mixed in the RhB solution, and the color turned red. The mixture was stirred at room temperature for $24 \mathrm{~h}$ under Ar protection, and the color turned yellow. The solvent was then removed by a rotary evaporator under reduced pressure. The yellow solid product was collected and purified by silica column chromatography with 1/1 ethyl acetate/hexane (v/v) as a white powder. ${ }^{1} \mathrm{H}$ NMR (300 MHz, $\left.\mathrm{CDCl}_{3}\right): \delta 8.03(\mathrm{~d}, J$ $=6.1 \mathrm{~Hz}, 1 \mathrm{H}), 7.60-7.50(\mathrm{~m}, 2 \mathrm{H}), 7.23(\mathrm{~s}, 1 \mathrm{H}), 6.95(\mathrm{t}, J=7.4 \mathrm{~Hz}, 1 \mathrm{H}), 6.64(\mathrm{~d}, J=8.7 \mathrm{~Hz}$, $2 \mathrm{H}), 6.55(\mathrm{~d}, J=8.3 \mathrm{~Hz}, 1 \mathrm{H}), 6.41(\mathrm{t}, J=7.5 \mathrm{~Hz}, 1 \mathrm{H}), 6.31(\mathrm{~d}, J=9.1 \mathrm{~Hz}, 2 \mathrm{H}), 6.26(\mathrm{~s}, 2 \mathrm{H})$, $6.09(\mathrm{~d}, J=7.9 \mathrm{~Hz}, 1 \mathrm{H}), 3.32(\mathrm{q}, J=7.1 \mathrm{~Hz}, 8 \mathrm{H}), 1.14(\mathrm{t}, J=7.0 \mathrm{~Hz}, 12 \mathrm{H})$.

OVCAR-8/ADR cells used as the multidrug resistant ovarian tumor cell line was seeded on slides. The mPEG-PLGA-BNN6 nanoparticle solution $(100 \mu \mathrm{g} / \mathrm{mL}$ with about $30 \mu \mathrm{g} / \mathrm{mL}$ BNN6) was added onto the slide. After incubation for $2 \mathrm{~h}$, the cells were washed with a PBS solution to remove free nanoparticles. Then, the slides were kept under $365 \mathrm{~nm}$ light exposure for 2 min to trigger NO release from BNN6. The RBSP was dispersed in DMSO to a concentration of $10 \mathrm{mM}$, diluted to $20 \mu \mathrm{M}$ in a cell culture medium, and added to the UV light treated cells for NO detection. The OVCAR-8/ADR cells were incubated with RBSP for $4 \mathrm{~h}$, and then the slides were imaged under a fluorescence microscope.

\subsection{Fluorescence Imaging of DOX Release in OVCAR-8/ADR MDR Cells}

The mPEG-PLGA-BNN6-DOX nanomedicine was incubated with OVCAR-8/ADR cells in a 96-well plate at a DOX concentration of $50 \mu \mathrm{g} / \mathrm{mL}$. The same amount of mPEG-PLGABNN6-DOX was dissolved in an acetonitrile solution and tested using high-performance liquid chromatography (HPLC, Agilent Technologies 1200) to calculate cell uptake of the nanomedicine $\left(C_{\text {before }}\right)$. After incubation for $2 \mathrm{~h}$, the excess free nanoparticles were collected by centrifugation and redissolved in acetonitrile for HPLC testing $\left(C_{\mathrm{after}}\right)$. The cells were washed with PBS and then replaced with cell culture medium. The amount of mPEG-PLGA-BNN6-DOX nanomedicine in the cells was calculated by subtracting $C_{\text {after }}$ from $C_{\text {before }}\left(C_{\text {before }}-C_{\text {after }}\right)$. The conditions for the HPLC method were as follows: solvent A consisted of $0.05 \%$ trifluoroacetic acid (TFA) in water, solvent B consisted of $0.05 \%$ (TFA) in acetonitrile, and the flow rate was $1 \mathrm{~mL} / \mathrm{min}$ with $30 \%$ solvent $\mathrm{B}$ and $70 \%$ solvent A.

The cells were exposed to $365 \mathrm{~nm}$ light for 2 min to trigger $\mathrm{NO}$ release and were then kept at $37^{\circ} \mathrm{C}$. Doxorubicin release was monitored at $1,12,24$, and $48 \mathrm{~h}$. The cells treated with mPEG-PLGA-BNN6-DOX without UV irradiation and the cells treated with free DOX were set as controls. SlideBook 5.0 software was utilized to calculate and analyze the cell fluorescence images. 


\subsection{Measurement of Cytotoxicity of mPEG-PLGA-BNN6-DOX Nanomedicine}

OVCAR-8/ADR cells were seeded at a concentration of $5 \times 10^{5}$ cells/well in a 96-well plate and incubated for $24 \mathrm{~h}$. Then, cells were treated with $100 \mu \mathrm{L}$ of mPEG-PLGA $(200,100,50$, $25,12.5,6.25$, and $0 \mu \mathrm{g} / \mathrm{mL}), 2 / 1 \mathrm{mPEG}-P L G A-B N N 6(300,150,75,37.5,18.75,9.375$, and $0 \mu \mathrm{g} / \mathrm{mL}), 4 / 1 \mathrm{mPEG}-\mathrm{PLGA}-\mathrm{DOX}(250,125,62.5,31.25,15.625,7.8125$, and $0 \mu \mathrm{g} /$ $\mathrm{mL})$, free DOX $(50,25,12.5,6.25,3.125,1.5625$, and $0 \mu \mathrm{g} / \mathrm{mL})$, or $4 / 2 / 1 \mathrm{mPEG}-\mathrm{PLGA}$ BNN6-DOX $(350,175,87.5,43.75,21.875,10.9375$, and $0 \mu \mathrm{g} / \mathrm{mL})$ for $2 \mathrm{~h}$. The treated cells were then washed with PBS; $100 \mu \mathrm{L}$ of RPMI 1640 medium was added, and the solution was irradiated with $365 \mathrm{~nm}$ light for $2 \mathrm{~min}$. After incubation for $48 \mathrm{~h}$, for the MTT (3-(4,5dimethylthiazol-2-yl)-2,5-diphenyltetrazolium) assay, the cell medium was replaced with $100 \mu \mathrm{L}$ of a $0.5 \mathrm{mg} / \mathrm{mL}$ medium solution of MTT and further incubated for $2 \mathrm{~h}$. The liquid was then removed, and $100 \mu \mathrm{L}$ of DMSO was added to each well to completely dissolve the crystals. An absorbance of $570 \mathrm{~nm}$ was selected to evaluate cytotoxicity.

\subsection{Statistical Analysis}

At least three independent samples were tested in each group, and $t$ test was done to perform a statistical analysis. $P<0.05$ was considered as statistically significant.

\section{RESULTS AND DISCUSSION}

\subsection{Synthesis and Characterization of mPEG-PLGA-BNN6 and mPEG-PLGA-BNN6-DOX Nanoparticles}

A microemulsion strategy has been widely applied to produce nanocarriers to load hydrophobic drugs or other molecules with a high loading efficiency. With such a method, microemulsions are generated with the help of surfactants which make oil and water an immiscible continuous medium to form an emulsion mixture droplet system with the size ranging from nano- to micrometers. In this research, the mPEG-PLGA copolymer (MW = 7600) was employed to load the thermally stable and water-insoluble NO donor BNN6 and chemotherapeutic drug doxorubicin. As shown in Figure 5A, the characteristic absorption peaks of BNN6 (around $370 \mathrm{~nm}$ ) and DOX (around $480 \mathrm{~nm}$ and a shoulder around $540 \mathrm{~nm}$ ) were observed in the UV-vis absorption spectrum of mPEG-PLGA-BNN6-DOX. We further utilized UV-vis spectrophotometry to detect the supernatant after the nanoparticles were washed and to calculate the DOX loading amount and efficiency (Figures S1-2). Because BNN6 is water insoluble and no solid precipitate was found in the solution of mPEG-PLGABNN6-DOX, we assumed quantitative entrapment of BNN6 into the nanoparticles.

\subsection{Characterization of mPEG-PLGA-BNN6-DOX Nanomedicine Before and After UV Light Treatment}

TEM and SEM images of the synthesized mPEG-PLGA-BNN6-DOX nanomedicine showed complete spherical morphology with good monodispersity and uniformity of the particles (Figures 2A and C). Most nanoparticles were less than $200 \mathrm{~nm}$ in size with a zeta potential around -7.0 (Figures $2 \mathrm{E}$ and F). Treatment with $365 \mathrm{~nm}$ UV light for 2 min resulted in most of the nanoparticles becoming collapsed or defected, presumably induced by NO release 
from the wrapped BNN6 donor as evidenced by the TEM (Figure 2B) and SEM (Figure 2D) images. A similar phenomenon was also reported by Sung et al. ${ }^{30}$

\subsection{NO Release Property and Stability of mPEG-PLGA-BNN6}

The classic Griess assay kit was utilized to detect NO release from the mPEG-PLGA-BNN6 nanoparticles after UV light irradiation. In our previous research, BNN6 was proven to be an efficient UV-vis light-responsive NO donor in PBS buffer, but the water insoluble property of BNN6 limits its biological applications. ${ }^{28}$ In this research, amphiphilic mPEG-PLGA allows efficient loading of BNN6 and solubilization of the NO donor in aqueous media. Synthesized mPEG-PLGA-BNN6 is highly responsive to the $365 \mathrm{~nm}$ light with fast NO release from the mPEG-PLGA nanoparticles. The LED lamp irradiation with visible light also triggered some release of NO over time (Figure 3C and Figure S3). Thus, mPEGPLGA-BNN6 is deemed to be a UV-vis light-responsive NO release material that is able to load the chemotherapeutic drug doxorubicin.

\subsection{DOX Release Behavior of mPEG-PLGA-BNN6-DOX Nanomedicine}

We used UV-vis absorbance of DOX at $490 \mathrm{~nm}$ to detect DOX release from mPEG-PLGABNN6-DOX after irradiation. After 2 min of UV light exposure, some pores shrank or collapsed on the nanoshell, and more than $60 \%$ of the wrapped doxorubicin was released within $48 \mathrm{~h}$ at $37^{\circ} \mathrm{C}$ in the dark (Figure 3D, black line, and Figure S4). As a control experiment, incubation of the same amount of mPEG-PLGA-BNN6-DOX at $37{ }^{\circ} \mathrm{C}$ for $96 \mathrm{~h}$ without UV light treatment resulted in the release of only $28 \%$ of the DOX (Figure 3D, red line, and Figure S4). The slower and spontaneous release was caused by hydrolysis of PLGA or by DOX leaking from the innate defect of the nanostructure.

\subsection{Intracellular NO Release Detection using an RBSP Fluorescence Probe}

Encouraged by the high efficiency of light triggered DOX release from mPEG-PLGABNN6-DOX, we investigated its application for cancer therapy. Intracellular NO release from mPEG-PLGA-BNN6 after UV light treatment was measured by an RBSP fluorescence probe (Figure 3B). In our previous research, ${ }^{24}$ we synthesized and investigated the RBSP nitric oxide sensor which is derived from rhodamine B fluorescent dye. The sensor exhibited a negligible fluorescence signal after synthesis. Its fluorescence signal was recovered immediately after binding with $\mathrm{NO}$ or nitrite. In the current study, incubation of doxorubicin resistant OVCAR-8/ADR cells with mPEG-PLGA-BNN6 nanoparticles and treatment with $365 \mathrm{~nm}$ UV light led to the fluorescence recovery of RBSP caused by NO release from BNN6. On the contrary, a negligible fluorescence signal was detected in the mPEG-PLGABNN6 control group without $365 \mathrm{~nm}$ light treatment (Figure 3A). These results indicate that mPEG-PLGA-BNN6 is an excellent light-responsive NO donor nanomaterial.

\subsection{Intracellular DOX Release in OVCAR-8/ADR MDR Cells}

The exact amount of mPEG-PLGA-BNN6-DOX nano-medicine in cells was obtained by the HPLC method. The results showed that cell uptake of DOX was about $34 \%\left(2.78 \mu \mathrm{g} / 10^{5}\right.$ cells) after $2 \mathrm{~h}$ of incubation (Figure 5B and Figure S6). All of the $365 \mathrm{~nm}$ light treated OVCAR-8/ADR cells were incubated at $37{ }^{\circ} \mathrm{C}$ for $96 \mathrm{~h}$. After $1 \mathrm{~h}$ of incubation, some red 
granular fluorescence signals in the cytoplasm were observed, which were attributed to DOX (around $490 \mathrm{~nm}$ ). DAPI ( $4^{\prime}, 6$-diamidino-2-phenylindole) was employed to stain the cell nucleus (Figures 4A1-A3). After incubation at $37{ }^{\circ} \mathrm{C}$ for $24 \mathrm{~h}$, some dispersed and weak red fluorescence signals were found in the cytoplasm and nucleus, indicating that some of the DOX had been released from the micelles and penetrated into the cell nucleus (Figures 4B1B3). After $48 \mathrm{~h}$ of incubation, most of the DOX was observed in the nucleus, and the growth and fission of cells were significantly inhibited (Figure 4C1-C3). Taken together, we conclude that the DOX release is caused by NO release from BNN6, which breaks the structure of the nanoparticles.

As a control experiment, OVCAR-8/ADR cells were incubated with the same concentration of PEG-PLGA-DOX nanoparticles but without UV light treatment. After $48 \mathrm{~h}$ of incubation, most of the red fluorescence signals from DOX still remained in the cytoplasm, suggesting that the nanoparticles did not release DOX to stain the nucleus (Figure 4D1-D3). The same amount of free DOX $(50 \mu \mathrm{g} / \mathrm{mL})$ was also incubated with OVCAR-8/ADR cells as another control. Because the cells are resistant to doxorubicin, only a weak DOX fluorescence signal was observed after $48 \mathrm{~h}$ of incubation (Figure 4E1-E3).

The cell fluorescence intensities of UV light treated mPEG-PLGA-BNN6-DOX, mPEGPLGA-BNN6-DOX without UV light treatment, and free DOX at $48 \mathrm{~h}$ after incubation were calculated and analyzed using the SlideBook 5.0 software (Figure 5C). The fluorescence intensity of free DOX dropped rapidly over time (Figure 5C, blue column), and that of mPEG-PLGA-BNN6-DOX without UV light treatment decreased slightly after $48 \mathrm{~h}$, likely due to some clearance of the nanoparticles from the cells (Figure 5C, red column). In the mPEG-PLGA-BNN6-DOX UV group, the fluorescence signal first increased and then decreased (Figure 5C, black column). The UV light breaks the nanostructure, releases DOX molecules, and leads to the initial increase in fluorescence signals and subsequent penetration of DOX through the nuclear membrane, which causes fission inhibition and cell apoptosis and eventually decreases fluorescence intensity.

\subsection{Cytotoxicity of mPEG-PLGA-BNN6-DOX}

The cytotoxicity of mPEG-PLGA-BNN6-DOX against the MDR ovarian cancer cell line OVCAR-8/ADR was investigated using an MTT assay (Figure 5D). The results showed that the nanocarrier mPEG-PLGA micelles had negligible cytotoxicity against OVCAR-8/ADR cells at a high concentration of $100 \mu \mathrm{g} / \mathrm{mL}$ (Figure 5D, red line). After mPEG-PLGA was loaded with BNN6, the cytotoxicity increased (Figure 5D, pink line), which was caused by NO release from BNN6. The same amount of free DOX (Figure 5D, blue line) or mPEGPLGA-loaded DOX generated weak toxicity to these MDR cells. However, after mPEGPLGA was loaded with both BNN6 and DOX, a substantially increased cytotoxicity compared to that of the other groups was observed (Figure 5D, green line) with an $\mathrm{IC}_{50}$ value around $20 \mu \mathrm{g} / \mathrm{mL}$ of the wrapped DOX. This strongly suggests that the NO generated from BNN6 reversed MDR and increased the potency of DOX.

As a reducing agent, NO reacts with ROS in the tumor tissue and relieves oxidative stress to inhibit the activation of tolerance and scavenging systems of tumor cells. Moreover, NO as a signal molecule is able to conjugate with the heme group of sGC and impact the downstream 
pathway. ${ }^{21-24} \mathrm{NO}$ is expected to be an auxiliary therapeutic molecule that is able to overcome tumor MDR. Graham's group reported that low concentrations of NO agents such as glyceryl trinitrate (GTN), diethylenetri-amine NO (DETA/NO), and isosorbide dinitrate (ISDN) could selectively inhibit hypoxia-induced MDR to DOX and paclitaxel. ${ }^{8}$

Furthermore, results from a Phase II clinical trial indicated that NO is a promising adjuvant with vinorelbine and cisplatin chemotherapy in stage IIIB/IV non-small cell lung cancer treatment. ${ }^{31}$ The GTN/NO donor treated patients showed increased response to the chemotherapeutics and longer time to progression. The expression of tumor MDR and the growth-related genes HIF-1, P-gp, and VEGF decreased in comparison with that of patients not treated with the NO donor. ${ }^{32}$ Sung et al. developed a $\mathrm{pH}$-responsive NO and camptothecin release system. The PLGA hollow microsphere was synthesized as a NONOate and CPT-11 carrier. Upon injection of this system into tumor tissue, the low $\mathrm{pH}$ environment of tumor tissues would degrade the encapsulated NONOate to form NO bubbles and trigger localized CPT-11 drug release to serve as a P-gp mediated MDR reversal agent. ${ }^{30}$

\section{CONCLUSIONS}

In this research, a biodegradable nanomedicine was developed based on an mPEG-PLGA copolymer wrapped with the UV- vis light-responsive nitric oxide donor BNN6 and the chemotherapeutic drug doxorubicin. This nanoformula is stable under physiological conditions and shows excellent UV-vis light response release properties. After NO release from BNN6 is triggered, gas is generated to break the nanoparticle shell and lead to the release of wrapped doxorubicin. NO functions to reverse the MDR of tumor cells and enhance the chemo-sensitization of DOX therapy. This multifunctional amphiphilic nanoparticle formula with the high surface density of $\mathrm{mPEG}$ is expected to have prolonged blood circulation time and facile tumor penetration properties in future anticancer treatment studies.

\section{Supplementary Material}

Refer to Web version on PubMed Central for supplementary material.

\section{Acknowledgments}

We thank the financial support from the Intramural Research Program, National Institute of Biomedical Imaging and Bioengineering, National Institutes of Health, the National Key Program for Developing Basic Research of China (Grant 2014CB744501), the NSFC (Grants 61271056, 61471168, and 61527806), the Shenzhen Basic Research Program (Grant JCYJ20160226110137243), and the State Scholarship Fund from the China Scholarship Council.

\section{REFERENCES}

1. Persidis A. Cancer Multidrug Resistance. Nat. Biotechnol. 1999; 17(1):94-95. [PubMed: 9920278]

2. Grandjean F, Brémaud L, Verdier M, Robert J, Ratinaud M-H. Sequential Gene Expression of Pglycoprotein (P-gp), Multidrug Resistance-Associated Protein (MRP) and Lung Resistance Protein: Functional Activity of P-gp and MRP Present in the Doxorubicin-Resistant Human K562 Cell Lines. Anti-Cancer Drugs. 2001; 12(3):247-258. [PubMed: 11290872] 
3. Nakanishi T, Ross DD. Breast Cancer Resistance Protein (BCRP/ABCG2): Its Role in Multidrug Resistance and Regulation of Its Gene Expression. Aizheng. 2012; 31(2):73.

4. Ueda K, Clark D, Chen C, Roninson I, Gottesman M, Pastan I. The Human Multidrug Resistance (mdr1) Gene. cDNA Cloning and Transcription Initiation. J. Biol. Chem. 1987; 262(2):505-508. [PubMed: 3027054]

5. Taniguchi K, Wada M, Kohno K, Nakamura T, Kawabe T, Kawakami M, Kagotani K, Okumura K, Akiyama S-i, Kuwano M. A Human Canalicular Multispecific Organic Anion Transporter (cMOAT) Gene is Overexpressed in Cisplatin-Resistant Human Cancer Cell Lines with Decreased Drug Accumulation. Cancer Res. 1996; 56(18):4124-4129. [PubMed: 8797578]

6. Schroeijers AB, Scheffer GL, Flens MJ, Meijer GA, Izquierdo MA, Van Der Valk P, Scheper RJ. Immunohistochem-ical Detection of the Human Major Vault Protein LRP with Two Monoclonal Antibodies in Formalin-Fixed, Paraffin-Embedded Tissues. Am. J. Pathol. 1998; 152(2):373. [PubMed: 9466563]

7. Comerford KM, Wallace TJ, Karhausen J, Louis NA, Montalto MC, Colgan SP. Hypoxia-Inducible Factor-1-Dependent Regulation of the Multidrug Resistance (MDR1) Gene. Cancer Res. 2002; 62(12):3387-3394. [PubMed: 12067980]

8. Brown JM, Wilson WR. Exploiting Tumour Hypoxia in Cancer Treatment. Nat. Rev. Cancer. 2004; 4(6):437-447. [PubMed: 15170446]

9. Frederiksen LJ, Sullivan R, Maxwell LR, Macdonald-Goodfellow SK, Adams MA, Bennett BM, Siemens DR, Graham CH. Chemosensitization of Cancer in vitro and in vivo by Nitric Oxide Signaling. Clin. Cancer Res. 2007; 13(7):2199-2206. [PubMed: 17404104]

10. Matthews NE, Adams MA, Maxwell LR, Gofton TE, Graham CH. Nitric Oxide-Mediated Regulation of Chemosensitivity in Cancer Cells. J. Natl. Cancer Inst. 2001; 93(24):1879-1885. [PubMed: 11752013]

11. Sullivan R, Graham CH. Hypoxia-Driven Selection of the Metastatic Phenotype. Cancer Metastasis Rev. 2007; 26(2):319-331. [PubMed: 17458507]

12. Liao D, Johnson RS. Hypoxia: A Key Regulator of Angiogenesis in Cancer. Cancer Metastasis Rev. 2007; 26(2):281-290. [PubMed: 17603752]

13. Pelicano H, Carney D, Huang P. ROS Stress in Cancer Cells and Therapeutic Implications. Drug Resist. Updates. 2004; 7(2):97-110.

14. Brizel DM, Sibley GS, Prosnitz LR, Scher RL, Dewhirst MW. Tumor Hypoxia Adversely Affects the Prognosis of Carcinoma of the Head and Neck. Int. J. Radiat. Oncol., Biol., Phys. 1997; 38(2): 285-289. [PubMed: 9226314]

15. Höckel M, Schlenger K, Aral B, Mitze M, Schäffer U, Vaupel P. Association Between Tumor Hypoxia and Malignant Progression in Advanced Cancer of the Uterine Cervix. Cancer Res. 1996; 56(19):4509-4515. [PubMed: 8813149]

16. Movsas B, Chapman JD, Horwitz EM, Pinover WH, Greenberg RE, Hanlon AL, Iyer R, Hanks GE. Hypoxic Regions Exist in Human Prostate Carcinoma. Urology. 1999; 53(1):11-18. [PubMed: 9886581]

17. Muir C, Adams M, Graham C. Nitric Oxide Attenuates Resistance to Doxorubicin in ThreeDimensional Aggregates of Human Breast Carcinoma Cells. Breast Cancer Res. Treat. 2006; 96(2):169-176. [PubMed: 16331349]

18. Ren Z, Gu X, Lu B, Chen Y, Chen G, Feng J, Lin J, Zhang Y, Peng H. Anticancer Efficacy of A Nitric Oxide-Modified Derivative of Bifendate Against Multidrug-Resistant Cancer Cells. J. Cell. Mol. Med. 2016:1.

19. Prasad VR, Reddy GD, Kathmann I, Amareswararao M, Peters G. Nitric oxide Releasing Acridone Carboxamide Derivatives as Reverters of Doxorubicin Resistance in MCF7/Dx Cancer Cells. Bioorg. Chem. 2016; 64:51-58. [PubMed: 26657603]

20. Zhang X, Tian G, Yin W, Wang L, Zheng X, Yan L, Li J, Su H, Chen C, Gu Z. Controllable Generation of Nitric Oxide by Near-Infrared-Sensitized Upconversion Nanoparticles for Tumor Therapy. Adv. Funct. Mater. 2015; 25(20):3049-3056.

21. Rapozzi V, Della Pietra E, Bonavida B. Dual Roles of Nitric Oxide in The Regulation of Tumor Cell Response and Resistance to Photodynamic Therapy. Redox Biol. 2015; 6:311-317. [PubMed: 26319434] 
22. Wink DA, Miranda KM, Espey MG, Pluta RM, Hewett SJ, Colton C, Vitek M, Feelisch M, Grisham MB. Mechanisms of the Antioxidant Effects of Nitric Oxide. Antioxid. Redox Signaling. 2001; 3(2):203-213.

23. Cole SP, Deeley RG. Transport of Glutathione and Glutathione Conjugates by MRP1. Trends Pharmacol. Sci. 2006; 27(8):438-446. [PubMed: 16820223]

24. Lando D, Peet DJ, Whelan DA, Gorman JJ, Whitelaw ML. Asparagine Hydroxylation of the HIF Transactivation Domain: A Hypoxic Switch. Science. 2002; 295(5556):858-861. [PubMed: 11823643]

25. Zhu H, Bunn HF. Oxygen Sensing and Signaling: Impact on the Regulation of Physiologically Important Genes. Respir. Physiol. 1999; 115(2):239-247. [PubMed: 10385037]

26. Ridnour LA, Isenberg JS, Espey MG, Thomas DD, Roberts DD, Wink DA. Nitric Oxide Regulates Angiogenesis Through a Functional Switch Involving Thrombospondin-1. Proc. Natl. Acad. Sci. U. S. A. 2005; 102(37):13147-13152. [PubMed: 16141331]

27. Samadi N, Abbadessa A, Di Stefano A, Van Nostrum C, Vermonden T, Rahimian S, Teunissen E, Van Steenbergen M, Amidi M, Hennink W. The Effect of Lauryl Capping Group on Protein Release and Degradation of Poly (d, l-lactic-co-glycolic acid) Particles. J. Controlled Release. 2013; 172(2):436-443.

28. Fan J, He N, He Q, Liu Y, Ma Y, Fu X, Liu Y, Huang P, Chen X. A Novel Self-Assembled Sandwich Nanomedicine for NIR-Responsive Release of NO. Nanoscale. 2015; 7(47):2005520062. [PubMed: 26568270]

29. Xue Z, Wu Z, Han S. A Selective Fluorogenic Sensor for Visual Detection of Nitrite. Anal. Methods. 2012; 4(7):2021-2026.

30. Chung MF, Liu HY, Lin KJ, Chia WT, Sung HW. A pH-Responsive Carrier System that Generates NO Bubbles to Trigger Drug Release and Reverse P-Glycoprotein-Mediated Multidrug Resistance. Angew. Chem. 2015; 127(34):10028-10031.

31. Yasuda H, Yamaya M, Nakayama K, Sasaki T, Ebihara S, Kanda A, Asada M, Inoue D, Suzuki T, Okazaki T. Randomized Phase II Trial Comparing Nitroglycerin Plus Vinorelbine and Cisplatin with Vinorelbine and Cisplatin Alone in Previously Untreated Stage IIIB/IV Non-Small-Cell Lung Cancer. J. Clin. Oncol. 2006; 24(4):688-694. [PubMed: 16446342]

32. Yasuda H, Nakayama K, Watanabe M, Suzuki S, Fuji H, Okinaga S, Kanda A, Zayasu K, Sasaki T, Asada M. Nitroglycerin Treatment May Enhance Chemosensitivity to Docetaxel and Carboplatin in Patients with Lung Adenocarcinoma. Clin. Cancer Res. 2006; 12(22):6748-6757. [PubMed: 17121895] 

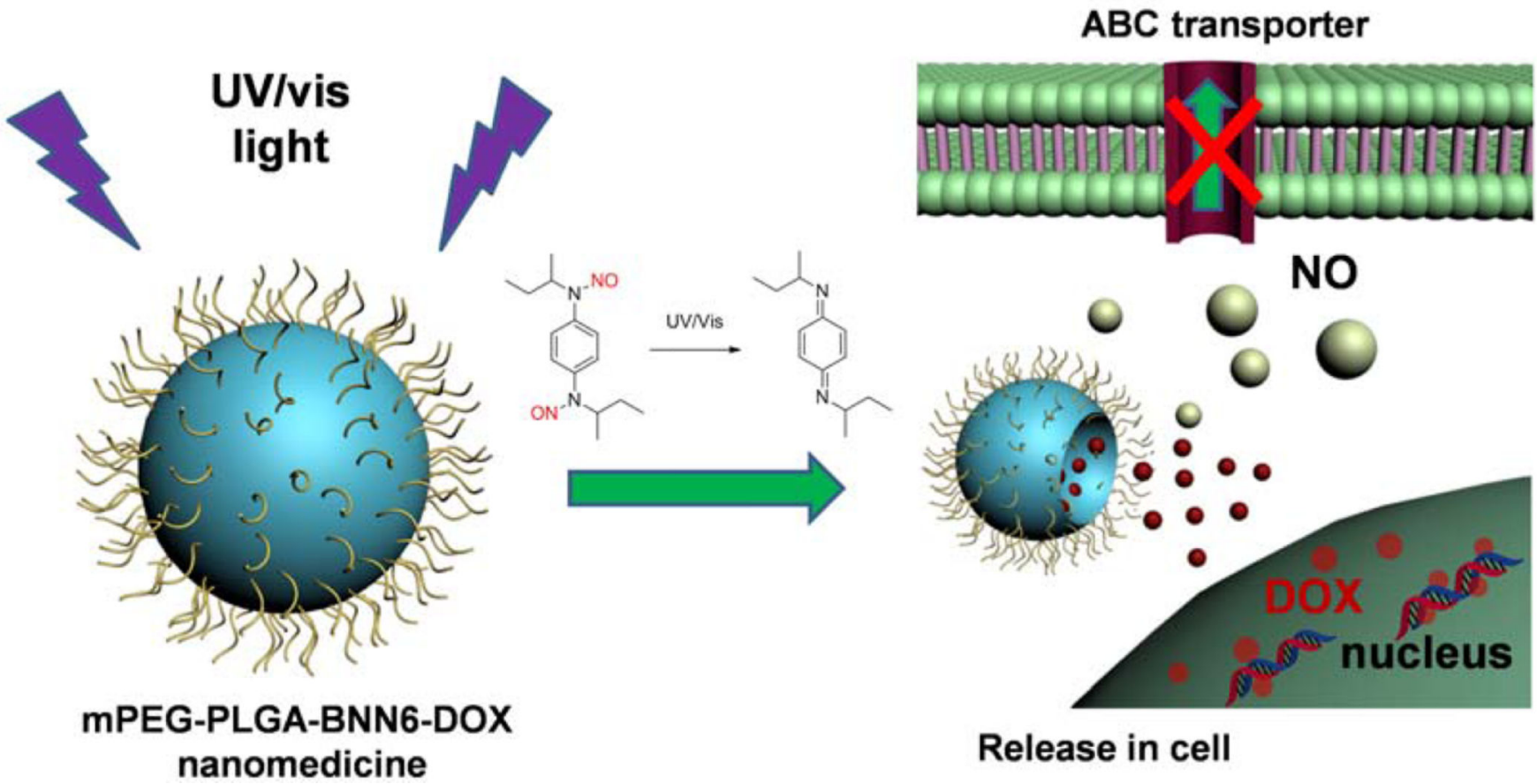

nanomedicine

Release in cell

Figure 1.

mPEG-PLGA-BNN6-DOX nanoparticles release NO and DOX inside cells. 

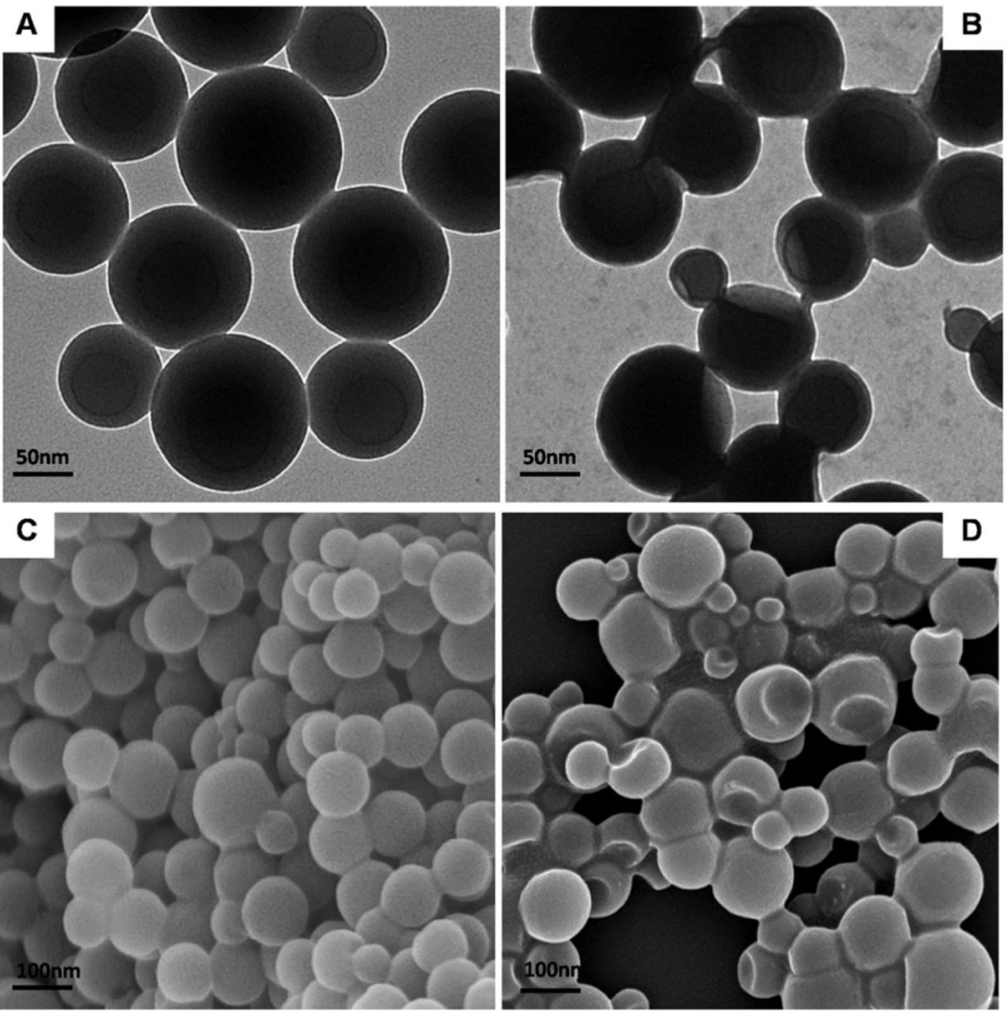
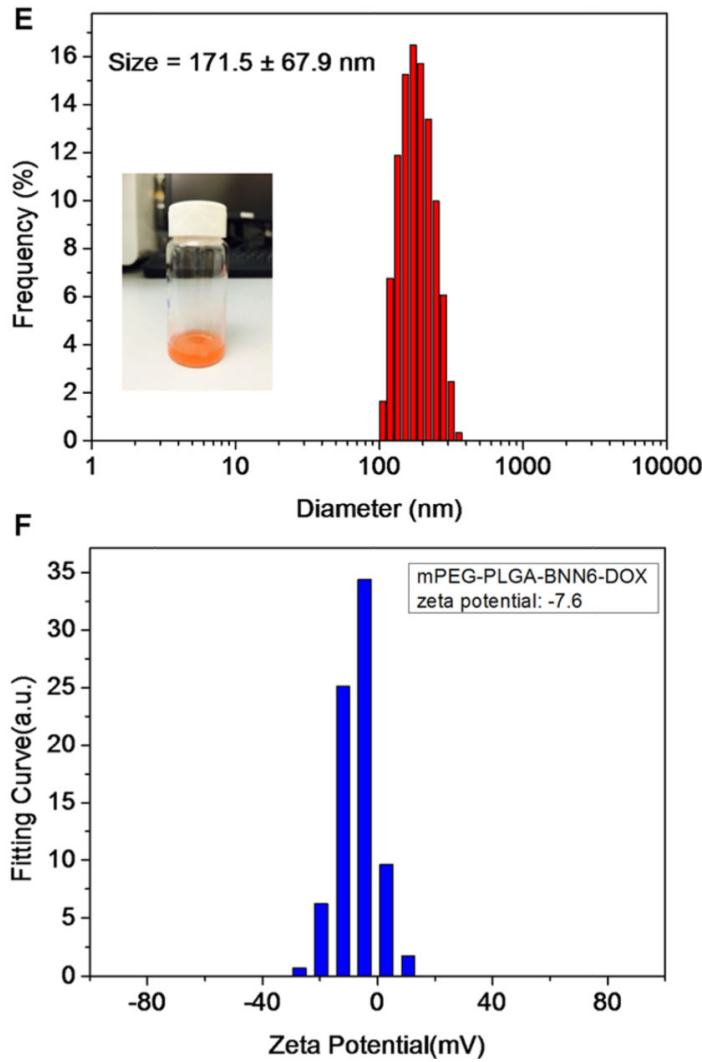

Figure 2.

TEM and SEM images of synthesized mPEG-PLGA-BNN6-DOX nanoparticles are presented in A and C, respectively, showing complete spherical morphology and good monodispersity of the particles. The size of most nanoparticles was less than $200 \mathrm{~nm}(\mathrm{E})$. After UV light irradiation for 2 min, some collapses or defects were observed in most of the nanoparticles as shown in B and D. (F) The zeta potential of mPEG-PLGA-BNN6-DOX nanoparticles. 
A
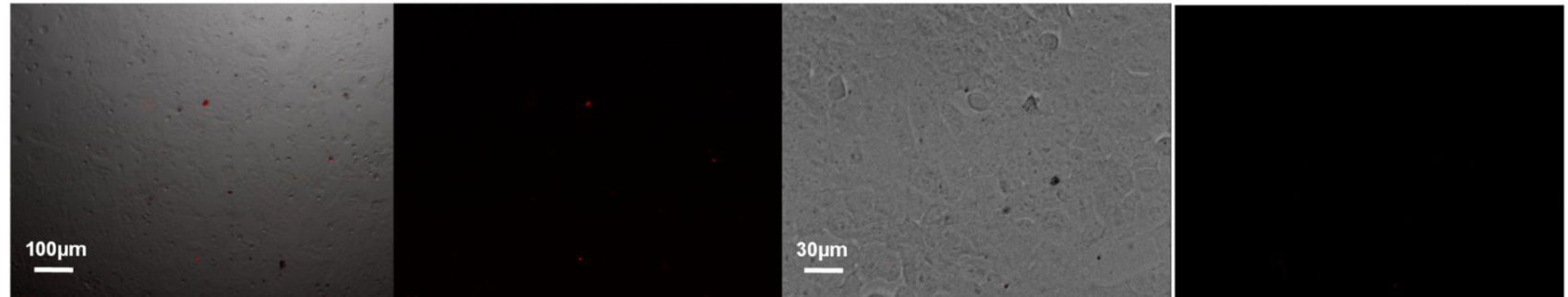

B
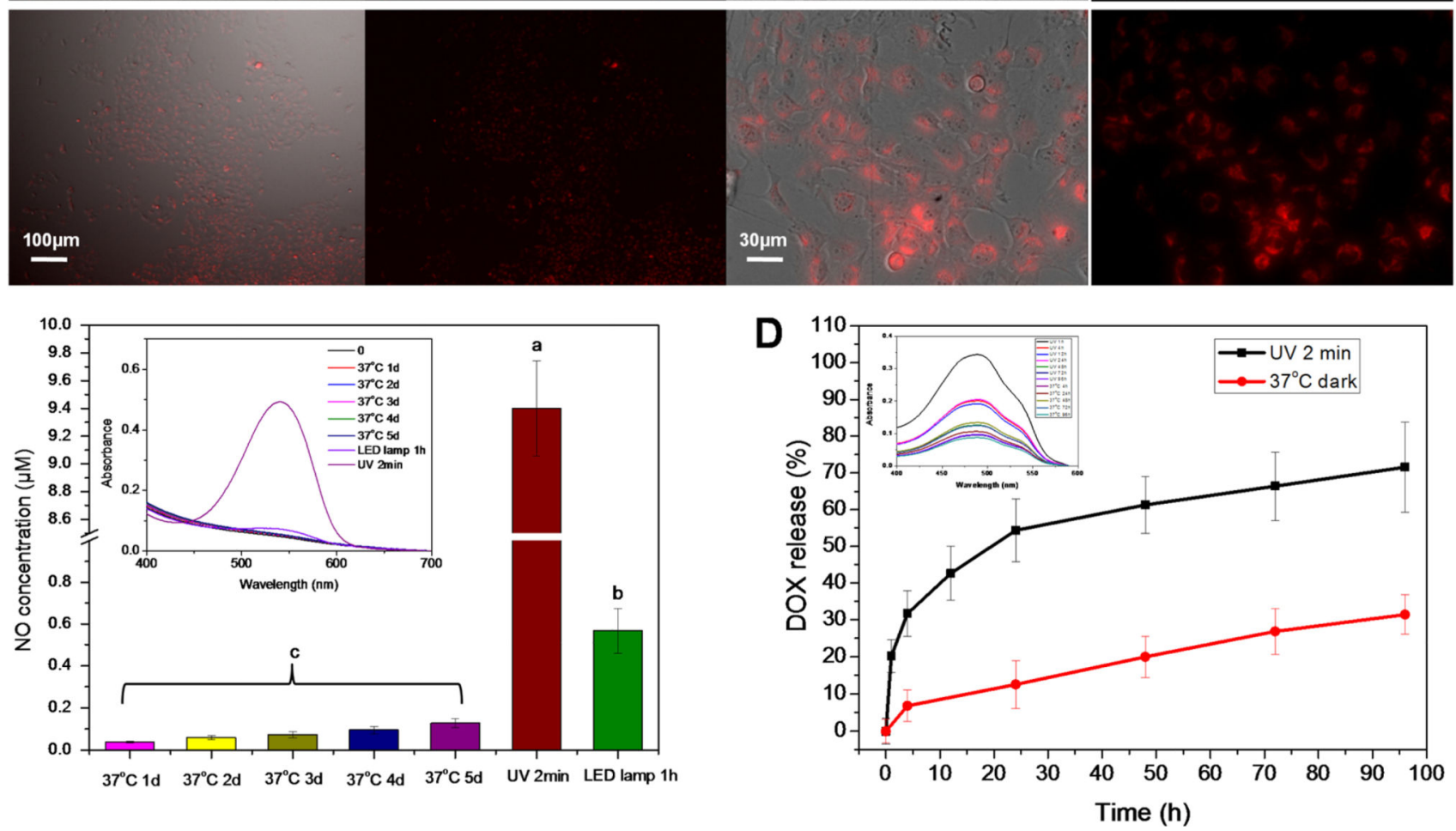

Figure 3.

An RBSP fluorescent probe was utilized to detect intracellular NO release from $\mathrm{mPEG}$ -

PLGA-BNN6 nanoparticles in OVCAR-8/ADR cells. There was no significant fluorescence signal detected in the mPEG-PLGA-BNN6 control group (without UV light treatment) (A), but fluorescence recovery of RBSP was observed in the cytoplasm after the cells were treated with $365 \mathrm{~nm}$ light (B). The Griess assay detected NO release from mPEG-PLGABNN6 under three different conditions (C). After being wrapped in mPEG-PLGA nanoparticles, BNN6 was still highly responsive to the $365 \mathrm{~nm}$ UV light and presented a fast NO release. Similarly, the nanoparticles were stable at $37^{\circ} \mathrm{C}$ (in PBS, pH 7.4). The LED lamp irradiation also generated NO after $1 \mathrm{~h}$ of irradiation. (D) After 2 min UV light exposure, more than $60 \%$ of the wrapped DOX leaked out in $48 \mathrm{~h}$ (D, black line). mPEGPLGA-BNN6-DOX without UV light treatment (D, red line) had only about $28 \%$ DOX release after $96 \mathrm{~h}$ of incubation at $37{ }^{\circ} \mathrm{C}$. 


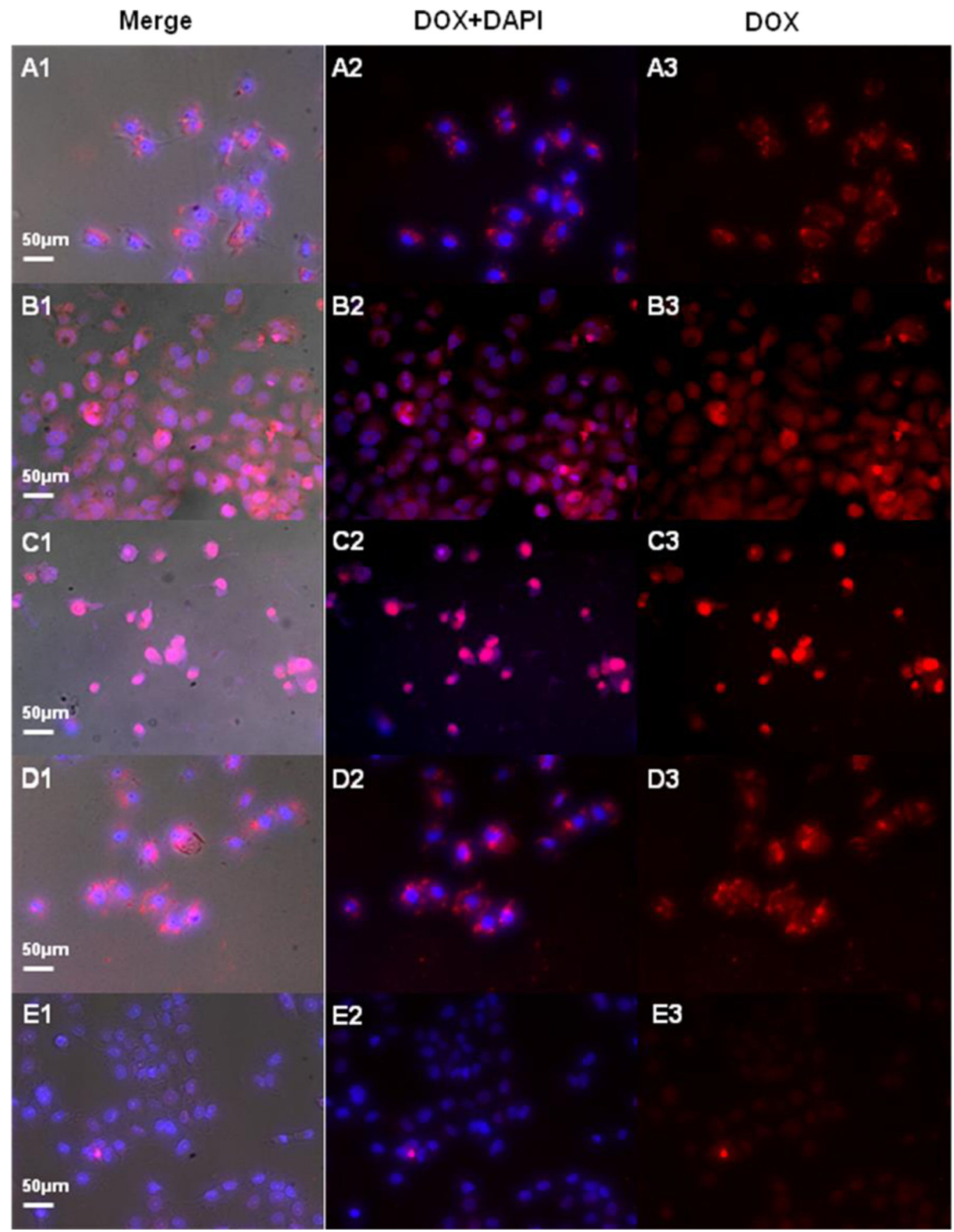

Figure 4.

UV light treated OVCAR-8/ADR cells were incubated at $37^{\circ} \mathrm{C}$ for $96 \mathrm{~h}$. After $1 \mathrm{~h}$ of incubation, some red granular fluorescence signals in the cytoplasm were observed. A DAPI stain showed the nucleus (A1-A3). After incubation at $37{ }^{\circ} \mathrm{C}$ for $24 \mathrm{~h}$, some dispersed red fluorescence signals were found in the cytoplasm and nucleus (B1-B3). After $48 \mathrm{~h}$ of incubation, most of the DOX signals were observed in the nucleus, and the growth and fission of cells were significantly inhibited (C1-C3). In the mPEG-PLGA-BNN6-DOX control group (without UV), most of the DOX fluorescence signals were still concentrated 
on the cytoplasm after $48 \mathrm{~h}$ of incubation (D1-D3). In the free DOX control group, only weak DOX fluorescence signals were found after $48 \mathrm{~h}$ of incubation (E1-E3). 

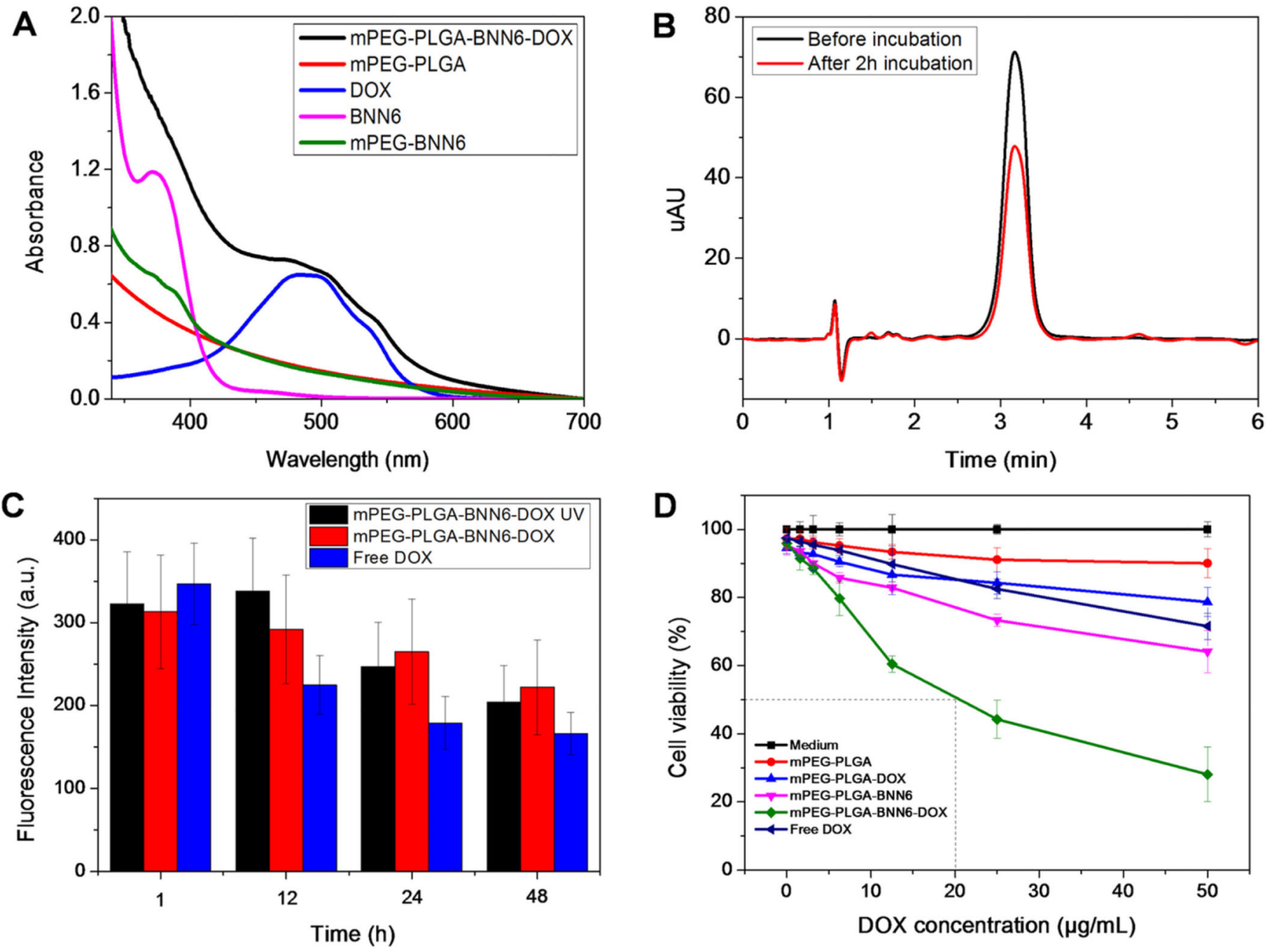

Figure 5.

(A) Characteristic absorption peaks of BNN6 around $370 \mathrm{~nm}, \mathrm{DOX}$ around $480 \mathrm{~nm}$, and a shoulder around $540 \mathrm{~nm}$ in the UV-vis spectra of mPEG-PLGA-BNN6-DOX. (B) The exact amount of mPEG-PLGA-BNN6-DOX nanomedicine in cells was calculated by an HPLC test (black line, before incubation; red line, after $2 \mathrm{~h}$ of incubation). (C) Cell fluorescence intensities of mPEG-PLGA-BNN6-DOX with UV, mPEG-PLGA-BNN6-DOX without UV, and free DOX over $48 \mathrm{~h}$. The fluorescence intensity of free DOX decreased quickly over time (C, blue column). The fluorescence intensity of mPEG-PLGA-BNN6-DOX without UV light treatment decreased slightly in $48 \mathrm{~h}$ (C, red column). In the mPEG-PLGA-BNN6DOX UV group, fluorescence signals first increased and then decreased (C, black column). (D) The cytotoxicity of mPEG-PLGA-BNN6-DOX nanomedicine against OVCAR-8/ADR was investigated using an MTT assay. The mPEG-PLGA micelles presented weak cytotoxicity against OVCAR-8/ADR cells at a concentration of $100 \mu \mathrm{g} / \mathrm{mL}$ (D, red line). After mPEG-PLGA was loaded with BNN6, the cytotoxicity increased (D, pink line). Similar amounts of free doxorubicin (D, blue line) or mPEG-PLGA-loaded DOX generated less toxicity in the MDR cells. After mPEG-PLGA was loaded with both BNN6 and DOX, a 
cytotoxicity was observed that was significantly increased over the other groups $(\mathrm{D}$, green line) with an $\mathrm{IC}_{50}$ value around $20 \mu \mathrm{g} / \mathrm{mL}$ of the wrapped DOX. 